\title{
“¡También existo!, creando ambientes inclusivos en alumnos de primaria con deprivación social"
}

\author{
"I also exist!, creating inclusive environments in primary school students \\ with social deprivation"
}

Belén Guadalupe Moguel Vidal ${ }^{*}$

\begin{abstract}
* Licenciada en Educacion Primaria por la Escuela Normal Urbana de Balancan, Tabasco. Maestra en Educación Especial con enfoque inclusivo por el Instituto de Educación Superior del Magisterio de Tabasco (IESMA) Trabaja actualmente en la escuela primaria "Profra. Rosario Maria Gutiérrez Eskildsen" en el Municipio de Centro, Tabasco.
\end{abstract}

\section{RESUMEN}

Es frecuente que los docentes, detecten que uno o varios de sus alumnos tienen poco interés o falta de atención en su clase, mismas que muchas veces son diseñadas sin pensar en el contexto que ellos viven lo cual obstaculiza considerablemente el principal objetivo que es aprender para la vida.

¡También existo! Es una expresión, sentimiento o actitud de aquellos estudiantes que no reciben una atención de calidad, esos que no se incluyen o no son incluidos en los equipos o grupos de juego, los alumnos que se aíslan o prefieren quedarse callados antes de preguntar cómo resolver las actividades de la clase.

Un estudiante poco motivado por el ambiente con un autoconcepto más bajo al de los demás requiere de mayor atención. Demanda estrategias que le permitan una convivencia áulica suficiente para su desenvolvimiento escolar. Solo el maestro podrá hacerlo sentir único y especial para que los demás así también lo crean y lo hagan sentir parte del grupo.

La observación es una herramienta que permite al docente detectar el interés de los alumnos por participar y aprender, y con ello, el riesgo de fracaso escolar. Esto le permitirá diseñar actividades especiales enfocadas en aquellos estudiantes con mayor rezago haciéndolos visibles ante todos los de la clase, descubrir sus capitales culturales y aprovecharlos para potencializar sus competencias. Sobre todo, es él quien busca ambientes de aprendizaje que generen la participación de todos.
La experiencia que relato se basa en una alumna de primer grado de primaria, procedente de una comunidad rural y con situación de deprivación social, por lo cual no podía acceder a los aprendizajes básicos marcados en el programa de estudios. Al observar sus actitudes y comportamientos me di a la tarea de poner más atención en ella y detectar sus áreas de oportunidades para intervenir de tal forma que potencialicé sus capitales culturales, con lo cual fue visibilizada en el aula y aceptada socialmente por sus compañeros.

Palabras clave: Conocimientos previos, deprivación social, capital cultural, autoconcepto, ambientes de aprendizaje.

\section{ABSTRACT}

It's common for educators to detect that various students have little interest and lack of attention in the classroom, classes are often designed without taking into consideration the student's lifestyle. It is considerably the reason it obstructs the main objective, which is how to learn for life.

"I too exist!" It's an expression, a feeling, or attitude for those students who do not receive quality care, those who isolate themselves and are not involved in group activities. They exclude themselves and prefer to stay quiet rather than ask how to resolve class activities.

Students less motivated by their environment and those who have lower self-esteem than others require of mayor attention and care. Educators should demand strategies that would allow them to coexist in the classroom for a better school involvement. Only the teacher can make the student feel unique and special for others to believe it so and making them feel part of the group.

Observation is a powerful tool that not only helps teachers detect the student's interest to learn and participate, but it also helps them reduce the risk of school failure. Observation lets 
Perspectivas Docentes 64

“También existo!, creando ambientes inclusivos en alumnos de primaria con deprivación social”

"I also exist!, creating inclusive environments in primary school students with social deprivation"

Belén Guadalupe Moguel Vidal

the teacher design special activities focused on those students who lag. This makes them visible to everyone in class, allowing them to discover their cultural strengths and heighten their capabilities. More than anything the teacher is the one ensuring a safe learning environment that allows everyone to participate.

My experience in this story is based on a first-grade female student who comes from a rural community and lacks social skills. For this reason, she did not have access to basic learning programs. After observing her behavior and attitude in the classroom, I made it a priority to pay more attention to her and find opportunities to intervene and strengthen her cultural and social skills. Thus, she became recognized in the classroom and socially accepted by all her classmates.

Keywords: Prior knowledge, social deprivation, cultural capital, self-concept, learning environments

\section{INTRODUCCIÓN}

El papel del docente propone contribuir al desarrollo de las habilidades, conocimientos y capacidades de los alumnos, busca potencializarlos y crear aprendizajes que pongan en práctica en su vida cotidiana. Esto no es siempre fácil, ya que algunos estudiantes presentan características personales, familiares o sociales que constituyen toda una barrera para el aprendizaje. Tal es el caso de la deprivación sociocultural, como veremos a continuación.

En el presente documento presento la experiencia con una alumna que al observarla durante los primeros días de clases noté un rezago educativo producto de la deprivación social, aislada de toda actividad escolar y de la convivencia entre sus compañeros.

Mi labor como docente fue crear ambientes inclusivos donde ella se sintiera parte del grupo, y sobre todo de la escuela. A su vez promoví actividades que favorecieran la socialización entre los alumnos de la clase, con modificaciones a los contenidos marcados en el programa de estudios, promoviendo que la estudiante fuera la protagonista de la clase, induciendo su participación a partir sus conocimientos previos, dando valor a sus producciones y logrando el interés de los estudiantes por conocer lo que la alumna con rezago educativo compartía, valorizándola ante los demás.
El papel del profesor que detecta a un alumno o alumnos que empiezan a apartarse de los demás, que no socializan y que se vuelven invisibles para sus compañeros, es demasiado importante. La atención adecuada genera un impacto positivo cuando el niño es estimulado y se da cuenta que a pesar de sus diferencias es igual de importante que cualquiera de sus compañeros y que el rechazo del cual es objeto es muchas veces inexistente y existe sólo cuando él mismo se aparta por haber crecido con un autoconcepto bajo.

Los niños que presentan problemas de índole familiar, económica, social, afectiva o cultural tienden a ser vulnerables en las relaciones que crean con sus compañeros de clase, ya que se observa una conducta de autosegregación como parte de un autoconcepto bajo propiciado por las circunstancias mencionadas. Como parte de las manifestaciones de este problema, estos alumnos tienden a desaparecer en clase, se aíslan, no participan y muchas veces se vuelven invisibles para el profesor. El problema radica en que estos alumnos empiezan siendo segregados por ellos mismos, luego por sus compañeros y por último por el profesor.

Es fácil observar a los niños con problemas para socializar con sus compañeros, mismos que son incapaces de incluirse en las actividades por miedo al rechazo o a la burla. Pueden presentar negligencia, abandono, sensibilidad, inseguridad 0 incluso violencia cuando son requeridos para las actividades del aula y sienten que son y al mismo tiempo no son parte de los alumnos de la clase. Tenemos que proporcionar a los niños un ambiente escolar sano, donde se desarrollen sus capacidades en un ambiente estable, sin importar su procedencia y los problemas que traen de casa. Es aquí donde quiero hacer hincapié en la importancia de centrarme en la responsabilidad magisterial de incluirlos, pues considero que no podemos tener un trabajo pedagógico correcto sin antes estimular a estos alumnos para lograr su participación escolar y cerrar las brechas culturales entre ellos y sus compañeros, ya que determinan en gran medida su avance pedagógico.

Cabe señalar que el caso que presento no es excepcional, sino más bien frecuente. En mi trayectoria como docente he sido partícipe de diferentes experiencias que me han llevado a cuestionarme por qué la mayoría los alumnos egresan de un grado escolar con carencias en las competencias básicas que marca el programa de estudios, si bien todos reciben la misma cátedra. Dónde está el conflicto que muchas veces los lleva al fracaso escolar o al rezago educativo y por tanto quién es el responsable de la mejora de los aprendizajes de los alumnos; serán las estrategias del docente o las características 
Perspectivas Docentes 64

“También existo!, creando ambientes inclusivos en alumnos de primaria con deprivación social”

"I also exist!, creating inclusive environments in primary school students with social deprivation"

Belén Guadalupe Moguel Vidal

de los alumnos que no nos permiten ser mediador en sus aprendizajes.

Si bien sabemos en todo grupo existe diversidad en los estudiantes, por el hecho de que cada individuo es diferente. Siempre tendremos heterogeneidad en nuestras salas de clases; entonces ¿dónde radica el problema? ¿qué pasa cuando el alumno es como un fantasma en las clases? ¿es culpa del estudiante? Antes de buscar una respuesta y querer hacer responsable a alguien, considero que el docente que toma en cuenta la diversidad debería obtener resultados satisfactorios y aunque muchas veces no ponemos atención a aquellos alumnos que más nos necesitan y que en las mayorías de las veces su destino es reprobar.

La diversidad no es tan solo un concepto, en verdad cada alumno obtiene sus aprendizajes por medio de sus experiencias y que cada uno aprenderá a su ritmo y mediante estímulos que obtengan por parte del medio escolar. Es por eso que el maestro debe estar preparado para las exigencias que éstos les demanden para que pueda propiciar las competencias en los alumnos. Pero, ¿qué pasa cuando no se trabaja en el aula cada una de las demandas que nos exigen los alumnos?

En este punto considero que se le da cabida a la exclusión y al rezago, pues cuando el profesor no tiene claro que las actividades no deben ser homogéneas, se da por entendido que la atención es para un grupo de alumnos con cualidades idénticas, lo cual no es posible, y no a todos en su diversidad como debería ser.

Este grupo de alumnos que no son tomados en cuenta en sus diferencias socioculturales, y quienes no hacen lo necesario para ser vistos, son aquellos que le cuestan más trabajo al maestro para enseñarles y que ellos aprendan. Estos niños son un reto en el aula por provenir de un contexto social más bajo que el del resto del grupo. En muchos casos sólo se atiende a los que sí muestran la intención deliberada de aprender, que en casa les ponen atención y les inculcan el valor de la educación, que entregan tareas, que pocas veces faltan a clases, que observan una conducta grata y dócil, pero ¿dónde quedan los alumnos con deprivación social? Aquellos carentes de expresividad de sus afectos, que provienen de un estrato social bajo, que por su comportamiento o conducta no crean empatía con el docente ni el profesor crea un ambiente donde ellos se sientan en confianza para propiciar aprendizajes.
Como lo señalan múltiples estudios, el papel del profesor ya no es transmitir conocimientos, sino ser promotor de aprendizajes (Pérez Ruiz \& Ferrer Meza, 2015; Levinson, Sandoval, \& Bertely, 2007; Peiró \& Beresaluce, 2012, entre muchos otros). Por tal motivo, detectar a un alumno o alumnos que empiezan a apartarse de los demás, que no socializan y se vuelven invisibles para sus compañeros, es demasiado importante. La atención adecuada genera un impacto positivo cuando el niño es estimulado y se da cuenta que a pesar de sus diferencias es igual de importante que cualquiera de sus compañeros y que el rechazo del cual es objeto es muchas veces inexistente y existe sólo cuando él mismo se aparta por haber crecido con un autoconcepto bajo.

Quisiera hacer visible la importancia de la observación constante hacia los alumnos, estar presentes en los logros y dificultades que presentan y ser andamiaje en sus constantes aprendizajes, por este motivo, pretendo que en este documento se registren acciones eficaces para atender y rescatar a aquellos alumnos con desventajas, los que por su condición socioeconómica no pueden verse (uniformados) igual al otro, que se aíslan y no creen en ellos. Considero que el papel que juega el docente es el punto medular para que estos alumnos marquen la diferencia en sus áreas de fortaleza de acuerdo a sus ritmos.

En este sentido, el objetivo de esta intervención fue "Visibilizar a aquellos estudiantes que presentan rezago educativo a causa de la deprivación social". Para ello, me propuse a) Identificar fortalezas en una estudiante marginada a causa de sus condiciones socioculturales de existencia, b) Aplicar estrategias educativas que generen ambientes inclusivos en el aula, para que los alumnos con deprivación social mejoren sus relaciones interpersonales y, c) Promover la participación de los alumnos en el aula, haciéndolos partícipes de actividades lúdicas que ayuden a la mejora de su autoconcepto.

\section{LA DEPRIVACIÓN SOCIOCULTURAL Y EL CAPITAL CULTURAL}

Para intervenir en la atención pedagógica de la niña cuyo caso aquí mostramos, hemos de definir dos conceptos centrales: la deprivación sociocultural y el capital cultural. Entendemos por deprivación

Un conjunto de circunstancias que pueden obstaculizar el normal desarrollo cognitivo, físico, emocional, y/o 
Perspectivas Docentes 64

“También existo!, creando ambientes inclusivos en alumnos de primaria con deprivación social”

"I also exist!, creating inclusive environments in primary school students with social deprivation"

Belén Guadalupe Moguel Vidal

social de las personas que viven inmersas en ambientes de pobreza cultural y/o material. Ésta situación genera una serie de circunstancias que hacen que estos niños no encuentren las mismas oportunidades de desarrollo personal, escolar, y laboral, (aunque no siempre las situaciones deprivativas llevan a procesos inadaptativos) (Federación de enseñanza de CCOO de Andalucía, 2009, pág. 1).

Respecto al capital cultural nos apoyamos en las enseñanzas de Pierre Bourdieu, (1987) quien desarrolla la idea de que cualquier elemento cultural que posea una persona, capaz de hacer valer para conseguir un lugar en el espacio social, puede entenderse como un capital. Esta idea, desarrollada anteriormente en su texto La distinción, plantea que

las prácticas culturales de las personas son un producto de -o se ven fuertemente influidas por- la interiorización inconsciente de esquemas cognitivos, valóricos y afectivos, que en su conjunto de lo que podemos entender como "disposiciones» y de las constricciones estructurales relativas principalmente a la dotación diferencial de los capitales cultural y económico. (Bourdieu, 1989, citado por Gayo, 2013, pág. 143)

Como puede verse, el reto de nuestra empresa consiste en recuperar las prácticas culturales de los estudiantes excluidos a causa de su deprivación sociocultural y convertir sus experiencias, por escasas y sencillas que puedan parecer, en capitales. Dicho esto, mencionaré que para promover la inclusión de la niña, a quien llamaré Nelly, me propuse desactivar los efectos de la deprivación que la mantenían aislada de la convivencia en aula y en general en la escuela. Para ello elaboré una serie de planeaciones didácticas que permitieran asignarle una posición protagónica durante una clase. Para ello promoví la capitalización de sus recursos culturales. Esto es lo que mostraré a continuación.

\section{RESULTADOS}

La interacción que hay entre los alumnos dentro y fuera del aula es, al mismo tiempo, una condición y un medio de aprendizaje. Es una condición porque sin ella, la participación mínima necesaria que los estudiantes deben vivir para apropiarse de las experiencias de aprendizaje no es posible. Es un medio, porque la comunicación que existe entre ellos colabora a reforzar los aprendizajes o movilizar nuevos, pues al estar en contacto social experimentan, conocen y son parte de experiencias que los llevan a desarrollarse como personas capaces de expresarse, dar sus puntos de vista y aprender del mismo contacto que tiene entre su entorno. La interacción es un medio de aprendizaje, toda sociedad que interactúa con otros aprende de forma significativa, y muy posiblemente lo lleva a la práctica.

El maestro que hace uso de estas interacciones como estrategias en su enseñanza logra que entre ellos se acepten, respeten su forma de pensar y aprendan a escuchar pues crean espacios donde ellos comparten lo que saben y a su vez movilizan y crean nuevos aprendizajes. Entre ellos van siendo parte de la inclusión de los mismos espacios escolares y contextuales de la propia comunidad.

En contraste, los alumnos con deprivación social, aquellos que son invisibles ante la sociedad y el espacio escolar por no tener temas de plática interesantes, no vestir igual o no sentirse como parte de ellos -por no sentirse incluidos en los temas curriculares-, muestran dificultades en la socialización con todo el contexto, ya que sienten no encajar dentro de los grupos y tienden a aislarse dentro del aula y los espacios escolares teniendo como consecuencia la falta de interés y el rezago educativo.

Al no tener interés por lo que pasa en el aula, por más interesante e interactiva que esté la clase, estos alumnos no lograrán apropiarse de los conocimientos. Un factor importante puede ser las actividades aisladas a su contexto 0 bien no estar favoreciendo sus intereses llevándolos al desinterés por aprender y asistir a la escuela, pues ésta no les está garantizando aprendizajes para la vida, esos conocimientos que les garantizarán poderse desenvolver en su medio sin dificultades y así sentir que la escuela tuvo un propósito en su vida.

Posiblemente el alumno con deprivación social quiera ser parte de la interacción social y participar con sus compañeros, pero estos a su vez no saben cómo ser empáticos con ellos pues para los demás no hay algo de interés que los lleve a interesarse por sus experiencias.

Si bien las interacciones son fundamentales para lograr lo aprendizajes en los niños y la sociedad, el docente debe motivar y propiciar que exista interés por aprender de todos. La motivación en el aula es fundamental y la pertenencia al grupo 
Perspectivas Docentes 64

“También existo!, creando ambientes inclusivos en alumnos de primaria con deprivación social”

"I also exist!, creating inclusive environments in primary school students with social deprivation"

Belén Guadalupe Moguel Vidal

de pares es un elemento motivador básico. A los alumnos que no socializan les es difícil aprender y más aún si las clases no son interesantes ni están al alcance contextual de los alumnos desfavorecidos.

Con esto me refiero, por ejemplo, a que cuando queremos trabajar un tema e introducimos conversaciones donde se requiere tener televisión, luz o medios de los cuales carecen estos alumnos, es erróneo pretender que participen si éstos no cuentan con las herramientas para participar, en este caso optan mejor por el silencio y así poco a poco se vuelven invisibles sin poder encajar en los temas de las clases.

Por tanto, mi interés como docente es visibilizar a aquellos estudiantes que presentan rezago educativo cuyo origen es la deprivación social. Para ello propongo estrategias que pueden favorecer su inclusión y aceptación en el grupo, así llegar hacer que los alumnos se sientan como parte del grupo y no como uno más que llega al aula solamente a sentarse.

Un ejemplo de lo anterior fue la experiencia que tuve con una alumna del primer grado de educación primaria, a quien llamaré Nely Manuela. Actualmente tiene 6 años de edad, vive en la Ranchería Plátano y Cacao 2da sección del municipio de Centro Tabasco. La alumna es hija de la señora Antonia, madre de cinco hijos. Su hogar está ubicado a las afueras de la comunidad, por lo cual ellos tienen que caminar aproximadamente un kilómetro dentro de platanares y ranchos para poder llegar a su hogar. Viven en condiciones muy precarias, carecen de los servicios de luz, agua potable y drenaje, su casa es de paredes de madera y techo de lámina, viven en una zona baja por lo que cuando llueve siempre se inundan. La casa no cuenta con divisiones entre cuartos, todos duermen en una misma área sobre catres y un colchón bastante maltratado y sucio. En este hogar también vive el papá de los últimos dos niños y la mamá de la señora Antonia, todas sus comidas las cocinan con leña ya que no cuentan con estufa de gas.

La familia se dedica al cultivo de frutos, ellos cosechan y todo lo llevan a vender al mercado de la ciudad de Villahermosa, de acuerdo a la entrevista realizada a la señora comento que cultivan papaya, guayabas, plátano, naranjas, guayaba, yuca, pitaya, ciruela, entre otros frutos que se dan en la región, destacando que la mayoría son frutos de temporada, así que de acuerdo a su cosecha ellos salen a venderlos.
En la familia todos los adultos son analfabetas, comentan que no asistieron a la escuela pero que a ella (la mamá de Nely Manuela) si le gusta que sus hijos asistan y aprendan para que más adelante sus hijos la ayuden con las ventas. Una característica muy importante de ella es la habilidad para sacar cuentas y dar el cambio ya que su trabajo de las ventas le exige ser muy audaz en las matemáticas.

Mi alumna ingresó al nivel primaria con mucha carencia de los conocimientos que debía haber consolidado en nivel preescolar. No conocía las vocales y no contaba más allá del número 10. Al ingresar a la escuela noté desde un principio la diferencia en el nivel de destrezas que presentaba. La niña se mostró muy tímida y su voz era tan baja que tenía que poner mi oído en su boca para lograr escuchar lo que me decía. Cabe mencionar que Nely Manuela es una niña de complexión delgada, cabello corto, muy delgado y escaso, mide aproximadamente un metro de altura. Ella y su hermana siempre llegan limpias y bien peinadas a sus clases, aunque sus uniformes no son nuevos ni con olor a suavizantes siempre cumplen con llevarlo y llevar los materiales que se requieren en la escuela. Cuando Manuela no tiene zapatos lleva sus sandalias, casi nunca falta a clases. Sin embargo está en el aula y muy pocas tareas las concluye con éxito. No se relaciona con nadie del grupo y siempre dice que ella no tiene amiguitas, situación que la lleva a aislarse en el aula y más aún en el receso donde sólo se mantenía en las afueras del salón parada observando como los demás jugaban.

En relación con los contenidos curriculares, estos en su mayoría están fuera de su nivel. Aunque intenta realizar sus tareas siempre se le tienen que realizar adecuaciones que estén a su alcance y pueda resolverlos exitosamente. Al realizar actividades de equipo, entre pares o actividades lúdicas, noto rechazo y exclusión por sus compañeros, posiblemente por su apariencia o porque ella también se muestra tímida al relacionarse. En estos casos recurro a la exhortación de incluir a su compañera en los equipos o yo misma llego a insertar a la alumna en los equipos incitando a la socialización e interacción entre ellos.

Realmente con esta forma de trabajo no notaba mucho avance. Esto me motivó a realizar actividades donde la niña fuera aceptada. Utilicé diversas estrategias hasta que opté por ocupar los contenidos curriculares y adaptarlos al contexto de la niña con rezago para tratar de rescatarla y a su vez hacerla protagonista del tema. Así sus compañeros notarían que ella tiene cosas interesantes que compartir y mostrar ante ellos para que también fuese aceptada en la clase. 
Perspectivas Docentes 64

“También existo!, creando ambientes inclusivos en alumnos de primaria con deprivación social”

"I also exist!, creating inclusive environments in primary school students with social deprivation"

Belén Guadalupe Moguel Vidal

Para ello, me di a la tarea de buscar contenidos curriculares que se apegaran al contexto de mi alumna con deprivación social. Aquellos que pudiera adaptar y así privilegiar a la niña para que se sintiera parte de la clase y por lo tanto interesada en participar.

En este caso tomé los temas del bloque 2 del libro de Exploración de la naturaleza y la sociedad, y en especial el contenido de "La naturaleza del lugar donde vivo". Con el conocimiento que tenía del contexto de mi alumna y de acuerdo a las actividades de su familia consideré que uno de los temas con los que podía abordar sus dificultades de socialización e inclusión estaba en vincular los temas del programa con las actividades que ellos realizan y tienen a su alcance.

Diseñé una planeación que adecué y adapté al entorno, buscando que la alumna se sintiera identificada con lo que se trabajaba. En un primer momento les pregunté sobre las plantas y animales que hay en sus casas, la intención principal era llevarlos a un clase paseo al domicilio de esta alumna pero por las condiciones y lejanía del camino para llegar, los padres de familia no autorizaron la visita, pues temían que a sus hijos le pudiese pasar algo, ya que no solo es caminar sino pasar por ranchos con pasto y platanares peligrando así la seguridad de los alumnos en general. Como segundo plan busqué desarrollar todas mis estrategias dentro del aula, pues lo que a mí más me interesaba era lograr que la niña se sintiera identificada y tomada en cuenta en las clases, que las actividades no fueran lejanas a ellas o poco atractivas.

Al cuestionarlos sobre las plantas y animales que hay en su casa, casi todos querían hablar al mismo tiempo. Se organizaron las participaciones y sobre todo busqué que Manuela hablara y comentara sobre lo cuestionado. Cabe mencionar que la alumna hablaba muy bajito por lo que incité a que su participación se repitiera apoyándola con lo que iba diciendo. Seguidamente pedí que escribieran y dibujaran las plantas y frutos que hubiera en su casa ya que no se escucharon todas las participaciones, así también que anotaran sus características.
La mayoría de los alumnos dibujaron los frutos que hay en sus casas. En general casi todos tenían plátano, mango, naranjas, etc. Nuevamente propicié que Manuela pasara a exponer su tema. Cuando ella mostró su trabajo vimos que en su casa había más frutos que los comunes, hasta alguno comentó, "ella nos ganó". La alumna platicó al grupo que en su casa hay muchas plantas como la guayaba, yuca, naranja, mango, guaya, plátano, cacao, icaco, papaya, etc. Pregunté si ellos conocían el fruto "icaco" a lo que respondieron que no sabían cómo era, ya que es un fruto nativo del estado y en realidad ni la maestra conocía el fruto. La niña respondió que era una frutita chica, rosadita y redondita, no pude profundizar más pues ignoraba completamente lo que era el "icaco", continúe preguntando a la niña sobre otro fruto que había dibujado en este caso la cuestione sobre "la pitaya". Vi que su dibujo es bastante similar y con características muy particulares a lo que es el fruto en realidad. Un niño le preguntó de qué color era, ella les dijo que por fuera color rosa y por dentro blanca con puntitos negros. La mayoría de los alumnos se acercaron a ver cómo eran los frutos que había dibujado. Considero que mis objetivos en ese momento se estaban cumpliendo, los alumnos habían notado que Manuela existía en el salón, pero sobre todo fue tomada en cuenta; en ese momento que noté que todo iba bastante bien, aproveché para que la alumna siguiera compartiendo sus conocimientos, continué preguntándole las características del fruto.

Para finalizar la sesión, los alumnos dibujaron los frutos que eran nuevos para ellos y a su vez con apoyo de Manuela se les dictaron sus nombres. Durante esta actividad, algunos niños le preguntaban y que les enseñara su dibujo o en su caso les dijera como lo podían hacer, de qué colores iba pintado y cómo era su forma. Al finalizar la actividad, todos los niños entregaron, la mayoría se acercó a lo que Manuela les iba explicando, considerando un logro en las relaciones interpersonales de los alumnos con la niña. 
“'También existo!, creando ambientes inclusivos en alumnos de primaria con deprivación social"

"I also exist!, creating inclusive environments in primary school students with social deprivation"

Foto 1. Actividad elaborada por Manuela

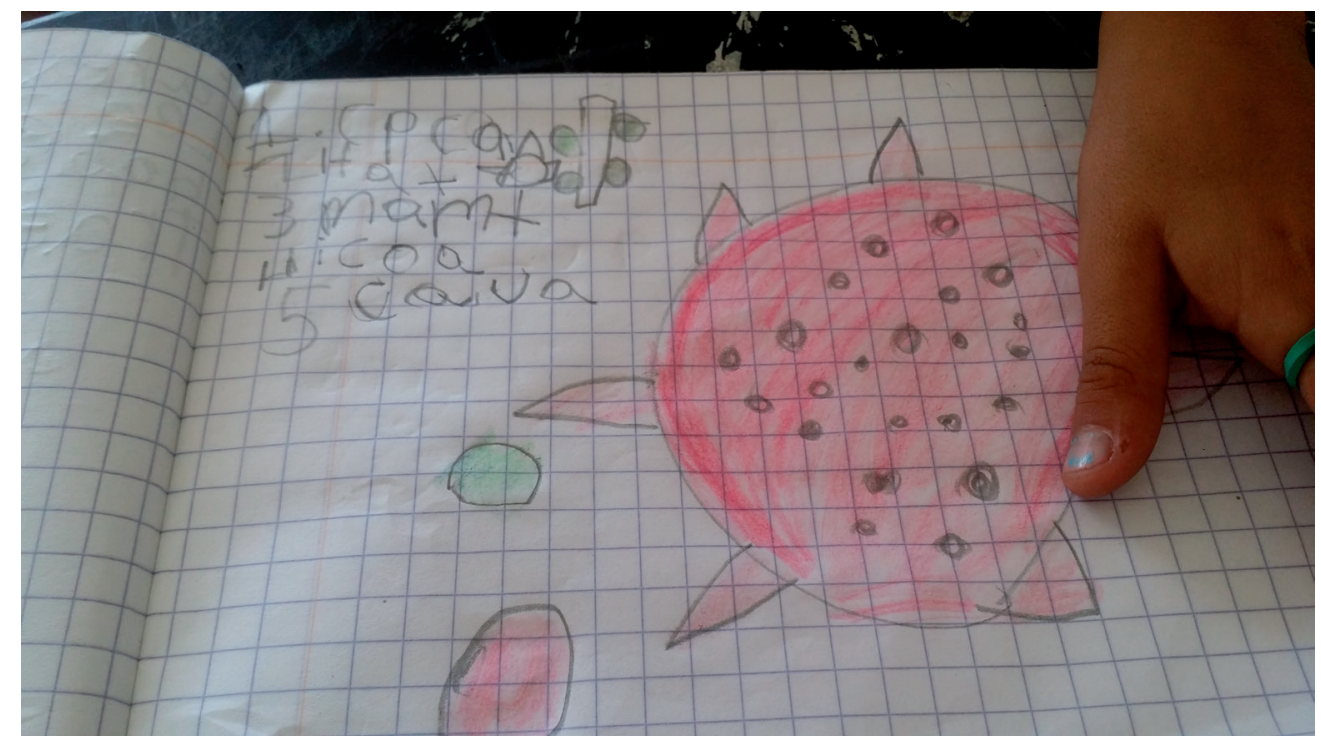

Fotos 2, 3. Producciones de estudiantes.
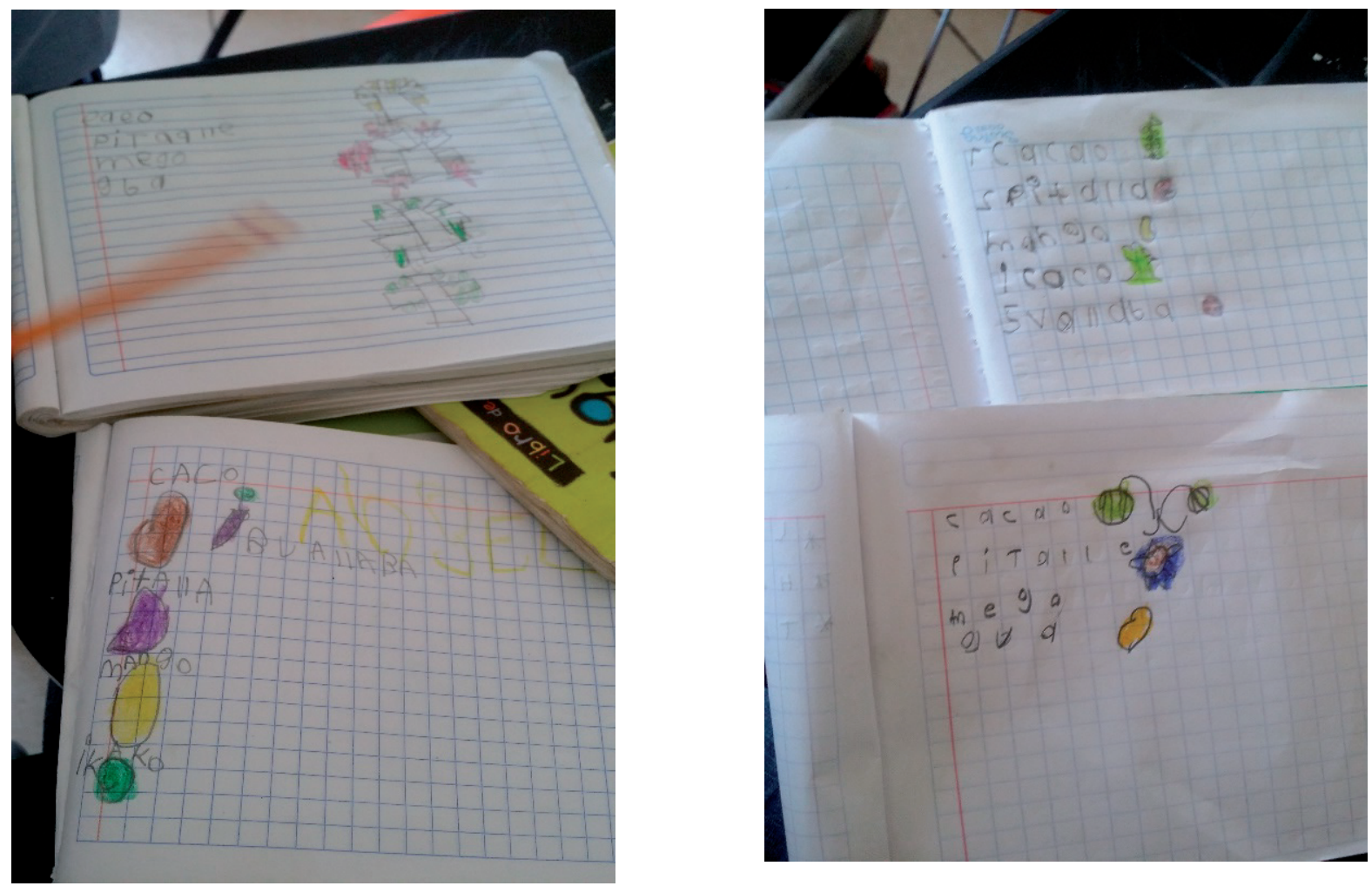

Fuente: Banco fotográfico del autor 
Perspectivas Docentes 64

“También existo!, creando ambientes inclusivos en alumnos de primaria con deprivación social”

"I also exist!, creating inclusive environments in primary school students with social deprivation"

Belén Guadalupe Moguel Vidal

Queda claro que los contenidos han sido diseñados como guía, para que el profesor los adecue y logre la mejora de los aprendizajes en los alumnos. Así pues, los temas que usé para hacer protagonista a mi alumna, fue el detonante para lograr avances significativos en ella y en el grupo. Favorecí en este caso a la niña con mayores necesidades, considerando los temas del entorno para que ella se sintiera interesada por aprender, sin imaginar que todos sus conocimientos eran muy especiales e únicos en el aula.

Cada alumno tiene necesidades diferentes, de esta forma como profesores podemos potencializar a nuestros alumnos por medio de los temas que nos propone los libros de textos, sin olvidar que pueden ser modificados y hechos a las necesidades que deseamos erradicar.

Posteriormente realicé actividades de socialización y juegos para corroborar que en verdad empezaba a ser aceptada, sin duda los resultados fueron buenos.

\section{DISCUSIÓN}

Hasta el momento logré registrar que en el proceso y aplicación de las actividades adaptadas en el aula la niña se desplaza más en el aula, su voz tiene mayor volumen, es más sociable, se integra y la integran sus compañeros a las actividades del aula, la ayudan si es necesario. Los niños en su mayoría la han aceptado en los juegos del receso, ya no se excluye ni se aparta de todos los demás.

Queda claro que aún hay mucho trabajo para lograr la inclusión en su totalidad, pero se ha trazado un gran avance en las relaciones interpersonales de Manuela. Su aceptación en el aula ha ayudado en sus participaciones e interés por aprender, ya no está invisible en el salón, ahora ella también es parte de éste.
Estas modificaciones en los contenidos fueron necesarios para lograr que la alumna se sintiera parte del grupo, y que sus compañeros notaran que cada uno de ellos tiene conocimientos que otros desconocemos y que esto nos hace especial entre todos.

A partir de las adaptaciones la mejoría en los aprendizajes de Manuela fueron significativos, pues no sólo fueron los alumnos quienes la toman en cuenta sino también en mí hubo un cambio de perspectiva en la enseñanza. No sólo busqué insertar a un alumno en el grupo y hacer como que todo estaría bien sin pensar en las necesidades de la niña con deprivación social; sino trabajé para que la alumna con mayores necesidades fuera incluida por los niños y por mí en las adecuaciones curriculares.

En este sentido, la estrategia desarrollada supera la propuesta de las adecuaciones curriculares que establecen programas compensadores de las dificultades individuales (García Vidal, 1993), al reconocer que la exclusión de Manuela no tiene su origen en una discapacidad o característica personal sino que es una situación de deprivación sociocultural (Sánchez Palomino \& Villegas, 1998), misma que, desde al ámbito escolar debe ser entendida y atendida como una característica de interculturalidad propia de la heterogeneidad que habita las aulas (García \& Lomba, 1997). Ello hará posible el trabajo con los alumnos, conductas sociales para mantener o reforzar su entorno (Pacheco \& Zarzo, 1993; Arcos Bravo, 1999; Moya Maya \& García Moro, 2001). Esto fue lo que se realizó para la atención de la deprivación de la niña. Es decir, más allá de planeación normativa que se entregó a la dirección del plantel en la semana correspondiente a la estrategia descrita, no hay ningún programa "especial". En todo caso, solo existe el presente reporte de trabajo. 


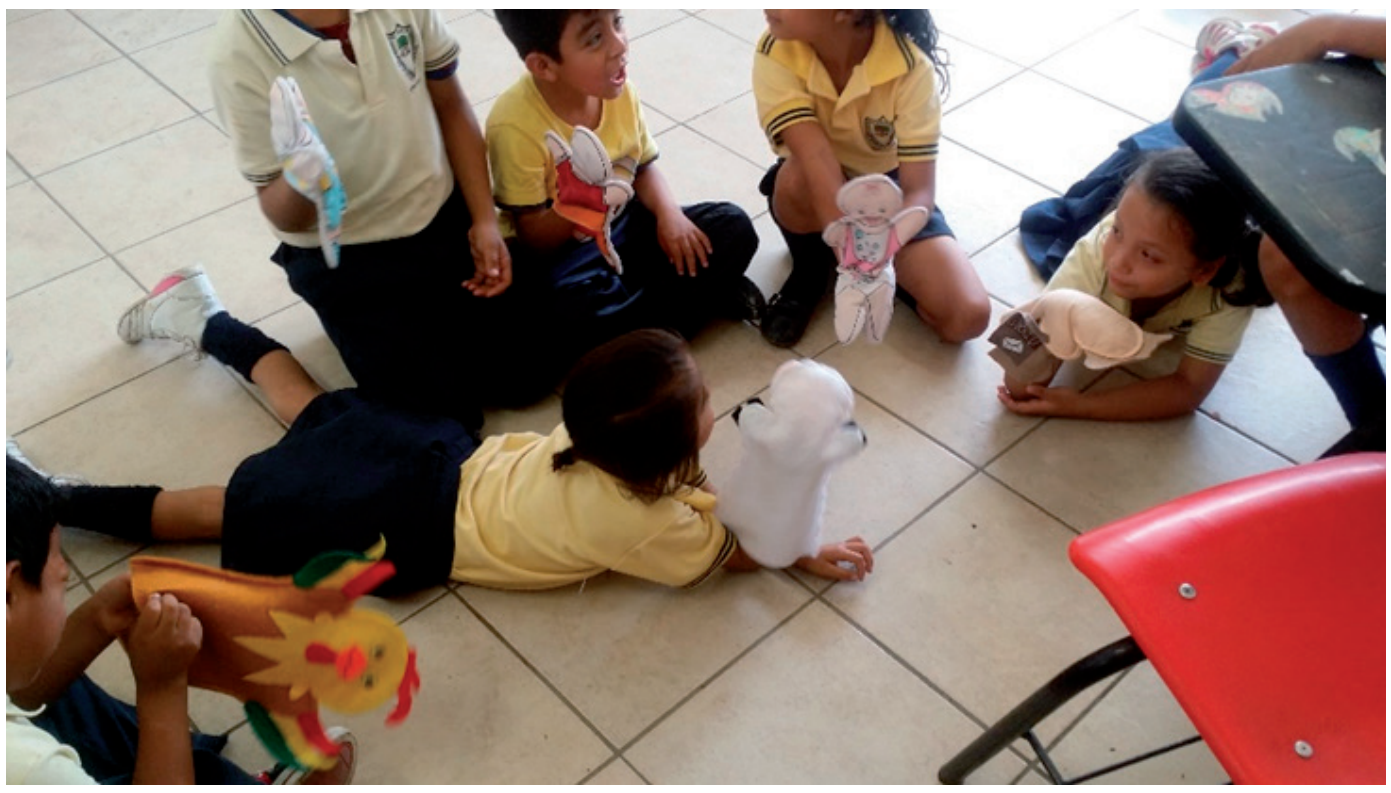

Foto 4. Actividad de socialización

Fuente: Banco fotográfico del autor

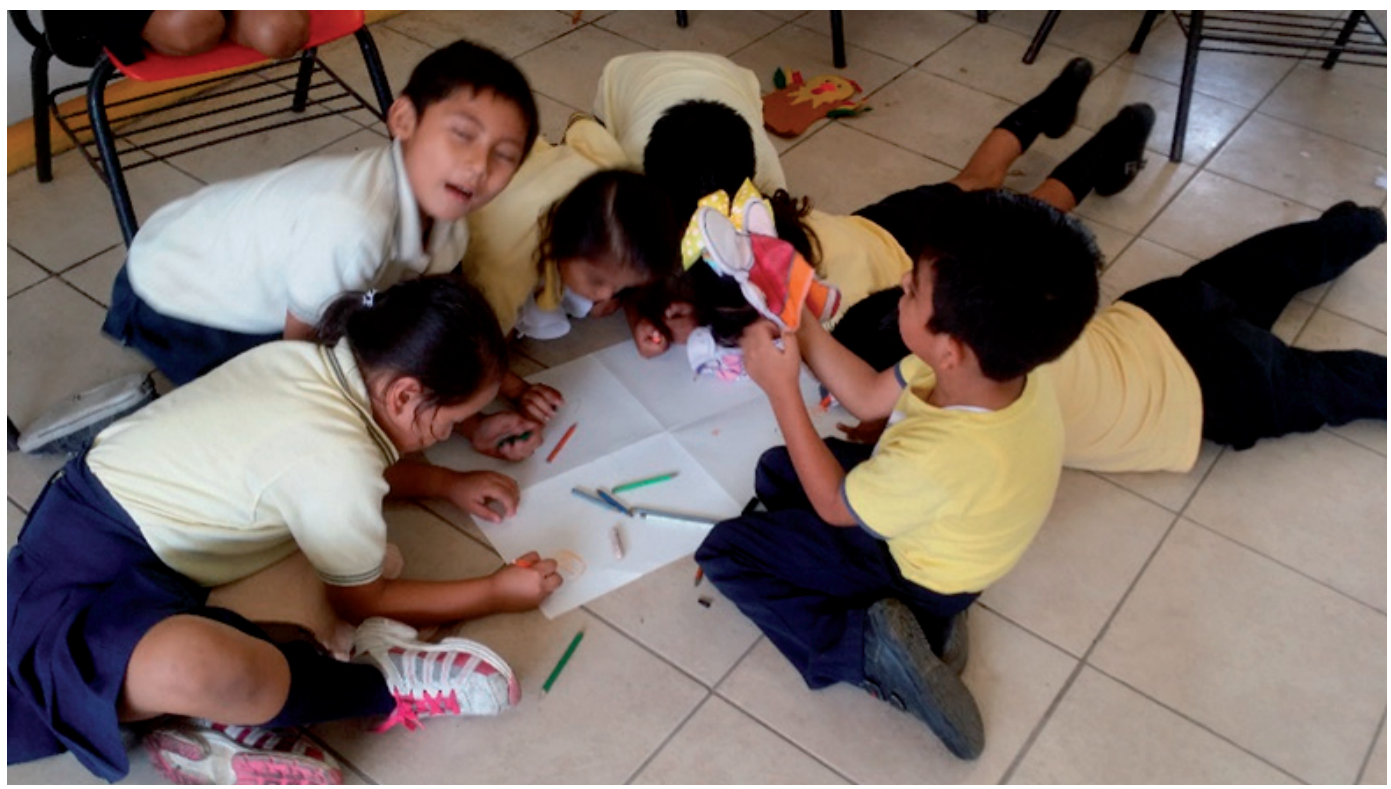

Foto 5. Trabajo en equipo

Fuente: Banco fotográfico del autor 
Foto 6. Actividad lúdica.

Fuente: Banco fotográfico del autor

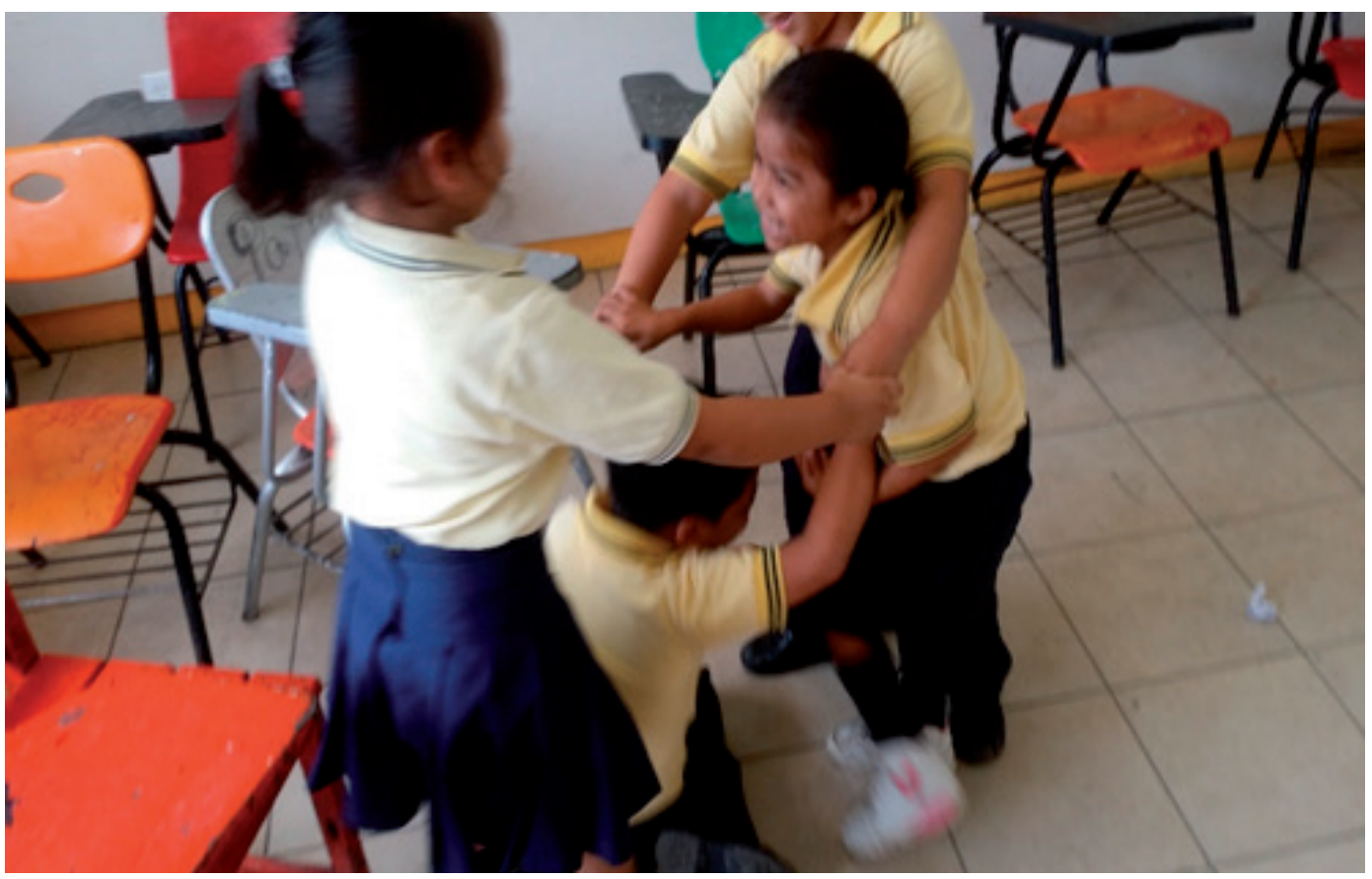

\section{CONCLUSIONES}

En todo grupo social existe diversidad y esto se observa claramente en un aula de clases, donde cada alumno trae consigo un bagaje cultural, ideológico, afectivo, etc. Todos y cada uno de los niños aporta al aula sus saberes preconcebidos y los socializa propiciando un ambiente que favorece el aprendizaje; esto siempre será posible cuando el docente esté consciente de que la diversidad entre sus alumnos existe, y que cada uno debe obtener los conocimientos de acuerdo con el nivel en el que se encuentra. Todos los alumnos deben llegar a los objetivos que se plantea el profesor lograr, sólo que cada uno lo irá logrando de acuerdo con sus fortalezas o limitantes.

Cabe mencionar que el programa curricular no está diseñado para que se lleve a cabo rigorosamente tal y como viene sugerido; cada docente es libre de diseñar sus planeaciones, adaptarla y crear ambientes de aprendizajes donde se favorezcan a todos los alumnos, privilegiando sin duda alguna al que más necesita. Los contenidos entonces son sugerencias para el trabajo en el aula, cada contexto es diferente y por tanto cada escuela o en su caso cada profesor es autónomo para realizar los cambios pertinentes siendo estos flexibles ante las necesidades que se le presenten.

En este sentido es importante señalar que la estrategia descrita no constituye una adecuación curricular ni un proyecto de inserción, integración o inclusión. La niña referida en este trabajo, Manuela, fue incluida en las actividades grupales y participa con entusiasmo en las sesiones de clase, y mantiene una buena relación de convivencia en el aula y fuera de ella, pero no porque se haya hecho ninguna adecuación curricular en el sentido referido por los autores citados en esta reflexión, sino porque se interpretó la flexibilidad del programa de estudios para la construcción de un ambiente inclusivo. Esa fue la apuesta. 
Perspectivas Docentes 64

“iTambién existo!, creando ambientes inclusivos en alumnos de primaria con deprivación social”

"I also exist!, creating inclusive environments in primary school students with social deprivation"

Belén Guadalupe Moguel Vidal

\section{REFERENCIAS}

Arcos Bravo, I. (1999). Las necesidades educativas especiales de la diversidad cultural en el aula desde unas estructuras interculturales: la recepción y la acogida. En A. Sánchez Palomino, \& Otros, Los desafíos de la educación especial en el umbral del siglo XXI. Almería: Universidad de Almería.

Bourdieu, P. (1987). Los Tres Estados del Capital Cultural. Sociológica, 11-17.

Bourdieu, P. (1989). La distinción. Criterios y bases sociales del gusto. Madrid: Taurus.

Federación de enseñanza de CCOO de Andalucía. (2009). Qué entenedemos por deprivación sociocultural. Temas para la educación, 1-10.

García Vidal, J. (1993). Guía para realizar adaptaciones curriculares. Málaga: Aljibe.

García, A., \& Lomba, S. (1997). ¿Educación compensatoria o educación intercultural? En P. Arnaiz Sánchez, \& R. De Haro Rodríguez, 10 años de integración en España: análisis de la realidad y perspectivas de futuro. Murcia: Universidad de Murcia.

Gayo, M. (2013). La teoría del capital cultural y la participación cultural de los jóvenes: el caso chileno como ejemplo. Ultima década(38), 141-171.
Levinson, B., Sandoval, E., \& Bertely, M. (2007). Etnografía de la educación: tendencias actuales. Revista Mexicana de Investigación Educativa, 12(34), 825-840.

Moya Maya, A., \& García Moro, F. J. (2001). Los alumnos que viven en ambientes desfavorecidos: respuestas ¿especiales? Educar(28), 205-212.

Pacheco, J., \& Zarzo, J. (1993). El niño y la niña con deprivación sociocultural. En R. Bautista, Necesidades educativas especiales. Málaga: Aljibe.

Peiró, S., \& Beresaluce, R. (2012). Subjetividad y educabilidad. Orientaciones para la praxis docente. Exedra(6), 105-122.

Pérez Ruiz, A., \& Ferrer Meza, R. y. (2015). Tiempo escolar y subjetividad: significaciones sobre la práctica docente en escuelas de tiempo completo. RMIE [online], 20(65), 507-527.

Sánchez Palomino, A., \& Villegas, F. (1998). Dificultades por deprivación socioculturaL. En A. Sánchez Palomino, \& J. A. Torres González, Educación especial II. Ámbitos específicos de intervención. Madrid: Pirámide. 